
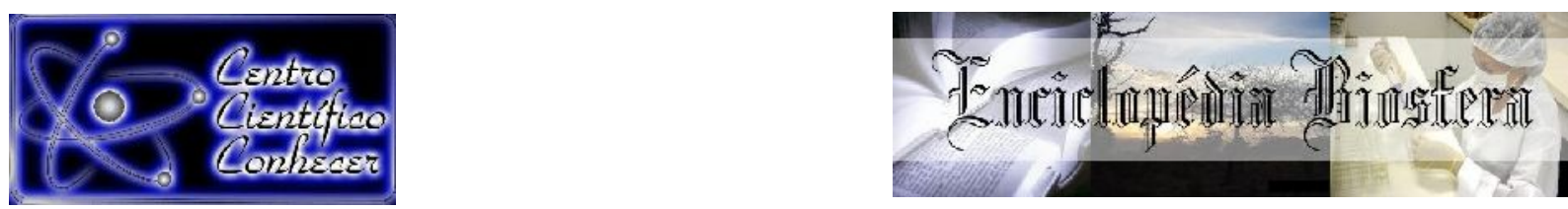

\title{
DOSES DE MÁXIMA EFICIÊNCIA TÉCNICA E ECONÔMICA DE NITROGÊNIO, FÓSFORO, POTÁSSIO E CALCÁRIO PARA O CAPIM-MARANDU
}

Andressa Gregolin Moreira¹, Jairo André Schlindwein², Elaine Cosma Fiorelli³, Iracy Soares de Aguiar ${ }^{4}$

1 Professora da área de Forragicultura e Pastagem do curso de Agronomia pela Faculdade Marechal Rondon (FARON), Campus de Vilhena, Vilhena-RO.

2 Professor Associado da área de Química do curso de Química pela Universidade Federal de Rondônia (UNIR), Campus de Porto Velho, Porto Velho-RO.

${ }^{3}$ Professora da área de Fertilidade do Solo do curso de Agronomia pela Universidade Federal de Rondônia (UNIR), Campus de Rolim de Moura, Rolim de Moura/RO.

${ }^{4}$ Professora Associada da área de Produção Animal do curso de Agronomia pela Universidade Federal de Rondônia (UNIR), Campus de Rolim de Moura, Rolim de Moura/RO.

E-mail: andressamoreira1@hotmail.com

Recebido em: 15/08/2021 - Aprovado em: 15/09/2021 - Publicado em: 30/09/2021

DOI: 10.18677/EnciBio 2021C16

trabalho licenciado sob licença Creative Commons Attribution-NonCommercial-NoDerivatives 4.0 International License.

\section{RESUMO}

O objetivo deste estudo foi determinar as doses de calcário, fósforo, potássio e nitrogênio para o rendimento de máxima eficiência técnica e máxima eficiência econômica do capim-marandu cultivado em solo de baixa fertilidade. O delineamento experimental adotado foi o de blocos ao acaso com quatro repetições. Os tratamentos constituíram-se de dois experimentos distintos em esquema fatorial. Um com cinco doses calcário $\left(0,1,2,4\right.$ e $\left.8 \mathrm{t} \mathrm{ha}^{-1}\right)$ e cinco doses de fósforo $(0,100,200,400$ e $800 \mathrm{~kg}$ de $\left.\mathrm{P}_{2} \mathrm{O}_{5} \mathrm{ha}^{-1}\right)$, o outro com cinco doses de potássio $\left(0,100,200,400\right.$ e $800 \mathrm{~kg}$ de $\mathrm{K}_{2} \mathrm{O}$ $\mathrm{ha}^{-1}$ ) e as doses de nitrogênio foram $0,50,100,200$ e $400 \mathrm{~kg}$ de $\mathrm{N} \mathrm{ha}^{-1}$ ), as doses de $\mathrm{N}$ foram parceladas em três subdoses e aplicadas nos meses de novembro, janeiro e março de cada ano. Os cortes para avaliação de massa seca do capim-marandu foram realizados nos meses de janeiro, março e junho de 2011 e 2012. O rendimento de máxima eficiência técnica foi estimada derivando-se as funções quadráticas de produção que melhor se ajustaram aos dados de cada experimento. As plantas responderam positivamente ao aumento das doses de calcário, fósforo, potássio e nitrogênio, aumentando a produtividade até a dose máxima técnica de 5874, 493, 351 e $209 \mathrm{~kg} \mathrm{ha}^{-1}$ respectivamente. As doses de máxima eficiência econômica foram menores que as da eficiência técnica, sendo de $5859 \mathrm{~kg} \mathrm{ha}^{-1}$ de calcário, $399 \mathrm{~kg} \mathrm{ha}^{-1}$ de $\mathrm{P}_{2} \mathrm{O}_{5}$, $223 \mathrm{~kg} \mathrm{ha}^{-1}$ de $\mathrm{K}_{2} \mathrm{O}$ e $183 \mathrm{~kg} \mathrm{ha}^{-1}$ de $\mathrm{N}$.

PALAVRAS-CHAVE: Adubação; Efeito residual; Manejo de pastagem.

\section{DOSES OF MAXIMUM TECHNICAL AND ECONOMIC EFFICIENCY OF LIMESTONE, PHOSPHORUS, POTASSIUM AND NITROGEN FOR CAPIM-MARANDU}

\section{ABSTRACT}

The objective of this study was to determine the doses of limestone, phosphorus, potassium and nitrogen for the yield of maximum technical efficiency and maximum economic efficiency in marandu grass cultivated in low fertility soil. The experimental ENCICLOPÉDIA BIOSFERA, Centro Científico Conhecer - Jandaia-GO, v.18 n.37; p. 191 
design was randomized blocks with four replications. The treatments consisted of two distinct experiments in factorial scheme. One with five limestone doses $(0,1,2,4$ and $8 \mathrm{t}$ $\mathrm{ha}^{-1}$ ) and five doses of phosphorus (0,100, 200, 400 and $800 \mathrm{~kg}$ of $\mathrm{P}_{2} \mathrm{O}_{5}$ ha $\left.{ }^{-1}\right)$, the other with five doses of potassium $\left(0,100,200,400\right.$ and $\left.800 \mathrm{~kg} \mathrm{of} \mathrm{K}_{2} \mathrm{O} \mathrm{ha}^{-1}\right)$ and doses of nitrogen $0,50,100,200$ and $400 \mathrm{~kg}$ of $\mathrm{N} \mathrm{ha}^{-1}$, the $\mathrm{N}$ doses were split in three subdoses and november, january and march of each year. The cuts for dry mass evaluation of marandu grass were made in January, March and June 2011 and 2012. The yield of maximum technical efficiency was estimated by deriving the quadratic production functions that best fit the data of each experiment. The plants responded positively to the increase of the lime, phosphorus, potassium and nitrogen doses, increasing the productivity up to the maximum technical dose of 5874, 493, 351 and $209 \mathrm{~kg} \mathrm{ha}^{-1}$ respectively. The highest economic efficiency rates were lower than those of technical efficiency, being $5859 \mathrm{~kg} \mathrm{ha}^{-1}$ limestone, $399 \mathrm{~kg} \mathrm{ha}^{-1} \mathrm{P}_{2} \mathrm{O}_{5}, 223 \mathrm{~kg} \mathrm{ha}^{-1} \mathrm{~K}_{2} \mathrm{O}$ and $183 \mathrm{~kg}$ $\mathrm{ha}^{-1} \mathrm{~N}$.

KEYWORDS: Fertilization; Residual effect; Pasture Management.

\section{INTRODUÇÃO}

A área cultivada com pastagens no Brasil é de cerca de 174 milhões de hectares, predominantemente utilizada na forma extensiva, para pecuária de corte. O rebanho bovino no Brasil em 2019 foi cerca de 213,5 milhões de cabeças sendo o segundo maior produtor de carne bovina do mundo, demonstrando assim a grande importância da atividade na economia brasileira (ANUALPEC, 2020). O rebanho bovino de Rondônia em 2019 foi de 14,1 milhões de cabeças, sendo 77,16\% para pecuária de corte (IDARON, 2018).

Dentre as gramíneas forrageiras tropicais mais utilizadas para alimentação de bovinos em Rondônia estão as forrageiras do gênero Brachiaria (Syn. Urochloa) cultivar marandu (capim-marandu), com cerca de $70 \%$ das pastagens cultivadas e ocupando em torno de 7 milhões de hectares. Essa área extensa de exploração da braquiária tem-se firmado pela capacidade de adaptação às diversas condições ambientais, capaz de se adaptar a solos de baixa fertilidade, ser tolerante a seca, boa capacidade de rebrota, além de responder a correção de acidez e adubação mineral (BARCELOS et al., 2011).

No Brasil e em Rondônia grande parte das pastagens encontram-se degradadas ou em vias de degradação e com a produtividade comprometida (PEREIRA et al., 2018; TERRA et al., 2019), devido ao manejo inadequado e a adubação de implantação e manutenção deficientes utilizadas na maioria das áreas com pastagens, não permitindo explorar todo o potencial genético das cultivares disponíveis para os pecuaristas (FREITAS et al., 2016). Segundo Schlindwein et al. (2012), as baixas produtividades obtidas na agropecuária em Rondônia devem estar relacionadas também à baixa fertilidade dos solos.

O maior desafio dos sistemas de produção de bovinos de corte a pasto está na utilização de tecnologias capazes de elevar a produtividade e a qualidade do produto (BARCELLOS et al., 2008). Para tanto, otimizar a utilização dos recursos forrageiros consiste nos principais objetivos de estratégia de manejo a serem adotados (HOTT et al., 2018).

A resposta de uma cultura ao uso de fertilizantes depende do estado de fertilidade do solo. Em geral, solos de baixa fertilidade apresentam alta probabilidade de resposta 
ao uso de fertilizantes (SOUSA; PEREIRA, 2016). Essa probabilidade de resposta diminui à medida que se adicionam doses crescentes do nutriente em déficit, até cessar ou diminuir significativamente próximo ao nível suficiente - nível crítico (TIESDALE et al., 1993).

O nível crítico pode ser estabelecido para uma resposta de máxima eficiência técnica (MET), que utiliza doses de fertilizantes para atingir máximo de rendimento de uma cultura, com os demais nutrientes essenciais em níveis adequados. Por outro lado, o nível crítico pode ser estabelecido também para uma resposta de máxima eficiência econômica (MEE), que utiliza doses de fertilizantes para atingir um máximo de rendimento do ponto de vista econômico (pode ser definido por vários critérios de disponibilidade de capital e taxa de risco, por exemplo) (SCHLINDWEIN; GIANELLO, 2005).

Apesar da reconhecida importância da calagem e adubação das pastagens, ainda são escassos os trabalhos na literatura que evidenciam os benefícios do calcário, fósforo, potássio e nitrogênio para a produção de capim (BULEGON et al., 2016; EGUCHI et al., 2017; FACTORI et al., 2018). Deste modo, o objetivo deste estudo foi determinar a dose de calcário, fósforo, potássio e nitrogênio para o rendimento de máxima eficiência técnica e máxima eficiência econômica no capim-marandu cultivado na Zona da Mata Rondoniense.

\section{MATERIAL E MÉTODOS}

Os experimentos foram instalados em julho de 2010, em uma propriedade particular no

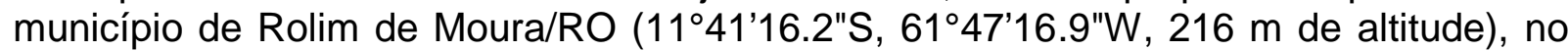
período compreendido entre julho de 2010 a janeiro de 2013. A classe de solo ocorrente na área é Latossolo Vermelho-Amarelo Distrófico de textura média, tendo como uso atual pastagem extensiva constituída por Brachiaria brizantha cv. Marandu para alimentação animal na pecuária de corte para fins comercial. Antes da instalação do experimento foi realizado a análise de solo das camadas de 0-0,10 e 0,10-0,20 m de profundidade, apresentando as seguintes características químicas:

TABELA 1. Atributos químicos do solo da área experimental em 2010.

\begin{tabular}{|c|c|c|c|c|c|c|c|c|c|}
\hline Profundidade & $\mathrm{pH}$ & $P^{1}$ & K & $\mathrm{Ca}$ & $\mathrm{Mg}$ & $\mathrm{Al}$ & $\mathrm{Al}+\mathrm{H}$ & $\mathrm{SB}^{2}$ & $\mathrm{~V}^{3}$ \\
\hline $\mathrm{m}$ & áqua & \multicolumn{7}{|c|}{$---\mathrm{mg} \mathrm{dm}^{-3}$} & $\%$ \\
\hline $0-0,10$ & 5,3 & 1,75 & 26 & 2,3 & 1,5 & 0,07 & 3,33 & 3,87 & 53 \\
\hline $0,10-0,20$ & 5,1 & 0,87 & 14 & 1,5 & 1,3 & 0,24 & 3,38 & 2,84 & 45 \\
\hline
\end{tabular}

Os experimentos apresentavam delineamento experimental em blocos ao acaso com quatro repetições, possuindo esquema fatorial com parcelas de $7 \times 7 \mathrm{~m}$. O primeiro experimento foi composto por doses calcário $\left(0,1,2,4\right.$ e $\left.8 \mathrm{t} \mathrm{ha}^{-1}\right)$ e doses de fósforo $(0$, $100,200,400$ e $800 \mathrm{~kg}$ de $\mathrm{P}_{2} \mathrm{O}_{5} \mathrm{ha}^{-1}$ ), ambos aplicados em superfície na instalação do experimento. No experimento um as doses de $\mathrm{K}_{2} \mathrm{O}$ foram na forma de cloreto de potássio e nitrogênio na forma de ureia, ambos na dose $200 \mathrm{~kg} \mathrm{ha}^{-1}$, sendo a dose de $\mathrm{K}_{2} \mathrm{O}$ aplicada somente na instalação do experimento e a dose de $\mathrm{N}$ aplicada anualmente e dividida em 3 subdoses iguais aplicadas em janeiro, março e novembro de 2011 e 2012.

O segundo experimento foi composto por doses de potássio na forma de cloreto de potássio $\left(0,100,200,400\right.$ e $800 \mathrm{~kg}$ de $\left.\mathrm{K}_{2} \mathrm{O} \mathrm{ha}{ }^{-1}\right)$ e doses de nitrogênio na forma de 
ureia $\left(0,50,100,200\right.$ e $400 \mathrm{~kg}$ de $\left.\mathrm{N} \mathrm{ha}^{-1}\right)$. As doses de $\mathrm{N}$ foram parceladas em três subdoses iguais e aplicadas nos meses de novembro, janeiro e marco de cada ano. As doses de calcário e $\mathrm{P}_{2} \mathrm{O}$ neste caso foram de $4 \mathrm{t} \mathrm{ha}^{-1}$ e $200 \mathrm{~kg} \mathrm{ha}^{-1}$, respectivamente, ambos aplicados em superfície na instalação do experimento.

Os cortes para avaliação de massa seca do capim-marandu foram realizados no mês de janeiro, março e junho de 2011 e 2012. Foram coletadas três subamostras de capim em cada parcela, utilizando um quadrado de ferro com $0,25 \mathrm{~m}^{2}$ de área interna, o qual era arremessado aleatoriamente na parcela útil de todos os tratamentos para compor uma amostra representativa, sendo coletado toda a forrageira existente acima de $0,10 \mathrm{~m}$ da superfície do solo. Em seguida, o material recolhido foi levado à estufa de ventilação forçada em temperatura de $65^{\circ} \mathrm{C}$ até atingir peso constante, para obtenção da massa seca.

Os resultados foram submetidos à análise de variância. As análises de regressão das respostas dos fatores isolados foram calculadas com o programa SIGMAPLOT 12.0. Ressalta-se que não se avaliou os efeitos das interações possíveis entre os fatores utilizados nos tratamentos. Partiu-se da premissa de que quando os demais nutrientes estão em quantidades adequadas, pode-se interpretar as respostas para adições de doses crescentes de um nutriente que estiver em falta (TAIZ et al., 2017). Assim, para avaliar as respostas de calcário no primeiro experimento, utilizou-se somente os dados da dose de $200 \mathrm{~kg} \mathrm{ha}^{-1}$ de $\mathrm{P}_{2} \mathrm{O}_{5}$ e para avaliar as respostas de fósforo, utilizou-se somente os dados da dose de $2 \mathrm{t} \mathrm{ha}^{-1}$ de calcário. Já no segundo experimento, para avaliar as respostas de potássio utilizou-se somente os dados da dose de $200 \mathrm{~kg} \mathrm{ha}^{-1}$ de nitrogênio e para avaliar as respostas de nitrogênio, utilizou-se somente os dados da dose de $200 \mathrm{~kg} \mathrm{ha}^{-1}$ de $\mathrm{K}_{2} \mathrm{O}$.

As doses de máxima eficiência técnica foram obtidas derivando-se e igualando a zero as funções quadráticas médias de produção que melhor se ajustaram aos dados de cada experimento (equação 1 e 2) (TIESDALE et al., 1993).

$$
\begin{aligned}
& y=c x^{2}+b x+a \\
& \frac{d y}{d x} \therefore 2 c x+b=0
\end{aligned}
$$

A dose de máxima eficiência econômica com critério de capital ilimitado é baseada no preço do quilo do fertilizante testado no experimento e no preço da arroba do boi em janeiro de 2013, que foi de $R \$ 91,73$ por arroba em Rondônia (AGROLINK, 2020). O preço do $\mathrm{kg}$ do fertilizante foi obtido em pesquisa no comércio varejista de Rolim de Moura/RO, em outubro de 2010, mês em que foi adquirido o fertilizante para o experimento, sendo de $R \$ 45,00$ t de calcário, $R \$ 4,00 \mathrm{~kg}$ de $\mathrm{P}_{2} \mathrm{O}_{5}, R \$ 4,00 \mathrm{~kg}$ de $\mathrm{K}_{2} \mathrm{O}$, $\mathrm{R} \$ 4,50 \mathrm{~kg}$ de $\mathrm{N}$. Ressalta-se que no experimento não foi avaliado o rendimento de carne a partir do pastejo de bovinos, o que se fez foi estimar a produção de carne a partir do rendimento de massa seca produzida pela pastagem (SILVA; CUNHA, 2003). Assim, segundo Barioni et al. (2007), para condições semelhantes de pastagem, a expectativa de ganho de peso médio diário é de $0,6 \mathrm{~kg} \mathrm{cab}^{-1} \mathrm{dia}^{-1}$ com consumo de 9,1 $\mathrm{kg} \mathrm{MS} \mathrm{dia}{ }^{-1}$.

A dose de máxima eficiência econômica com critério de capital ilimitado (MEE) é baseada no preço do $\mathrm{kg}$ do fertilizante (f) e no preço da arroba do boi gordo (v). Esses valores são aplicados nas equações médias derivadas das funções da receita (equação 3 e 4) (TIESDALE et al., 1993). 


$$
\begin{aligned}
& y=\mathrm{v}\left(c x^{2}+b x+a\right)-f \\
& \frac{d y}{d x} \therefore v(2 c x+b)-f=0
\end{aligned}
$$

O custo do fertilizante é composto pelo valor de mercado do produto, mais os custos financeiros e de transporte. O preço da arroba do boi gordo é composto pelo valor de venda, menos os custos do sal mineral, vacinas, vermífugo e compra do bezerro.

\section{RESULTADOS E DISCUSSÃO}

As funções de produção de massa seca do capim-marandu avaliadas nos cortes dos meses de janeiro, março e junho dos anos de 2011 e 2012 foram todas significativas e demonstram que as adições de doses crescentes de fósforo (Figura 1), calcário (Figura 2), nitrogênio (Figura 3) e potássio (Figura 4) aumentaram a produção de massa seca.

FIGURA 1. Rendimento de massa seca do capim-marandu nos meses de janeiro, março e junho de 2011 e 2012, com doses crescentes de $\mathrm{P}_{2} \mathrm{O}_{5}$.
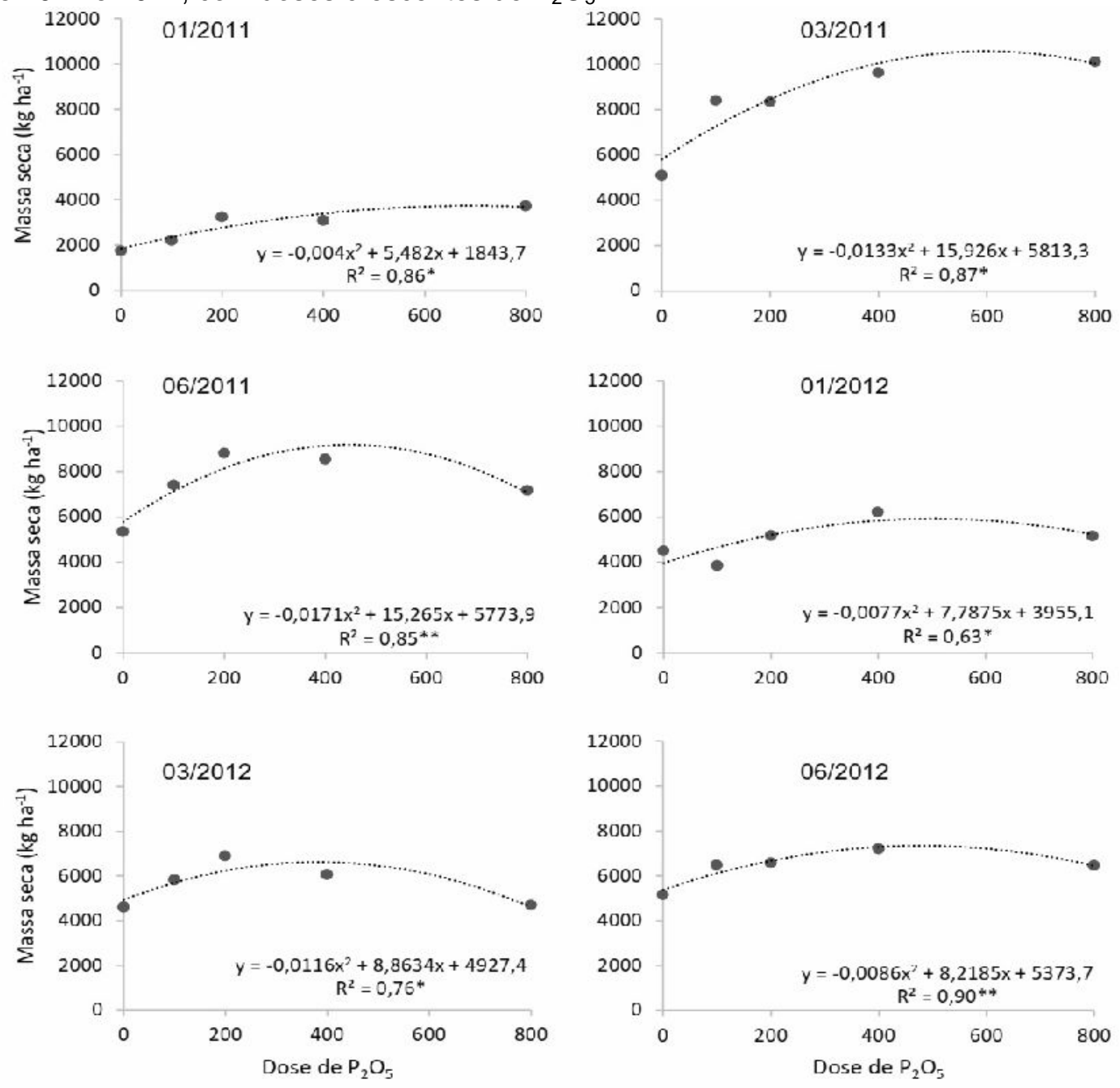

${ }^{* *}$ significativo a $1 \%,{ }^{*}$ significativo a $5 \%$.

Fonte: os autores. 
FIGURA 2. Rendimento de massa seca do capim-marandu nos meses de janeiro, março e junho de 2011 e 2012, com doses crescentes de calcário.
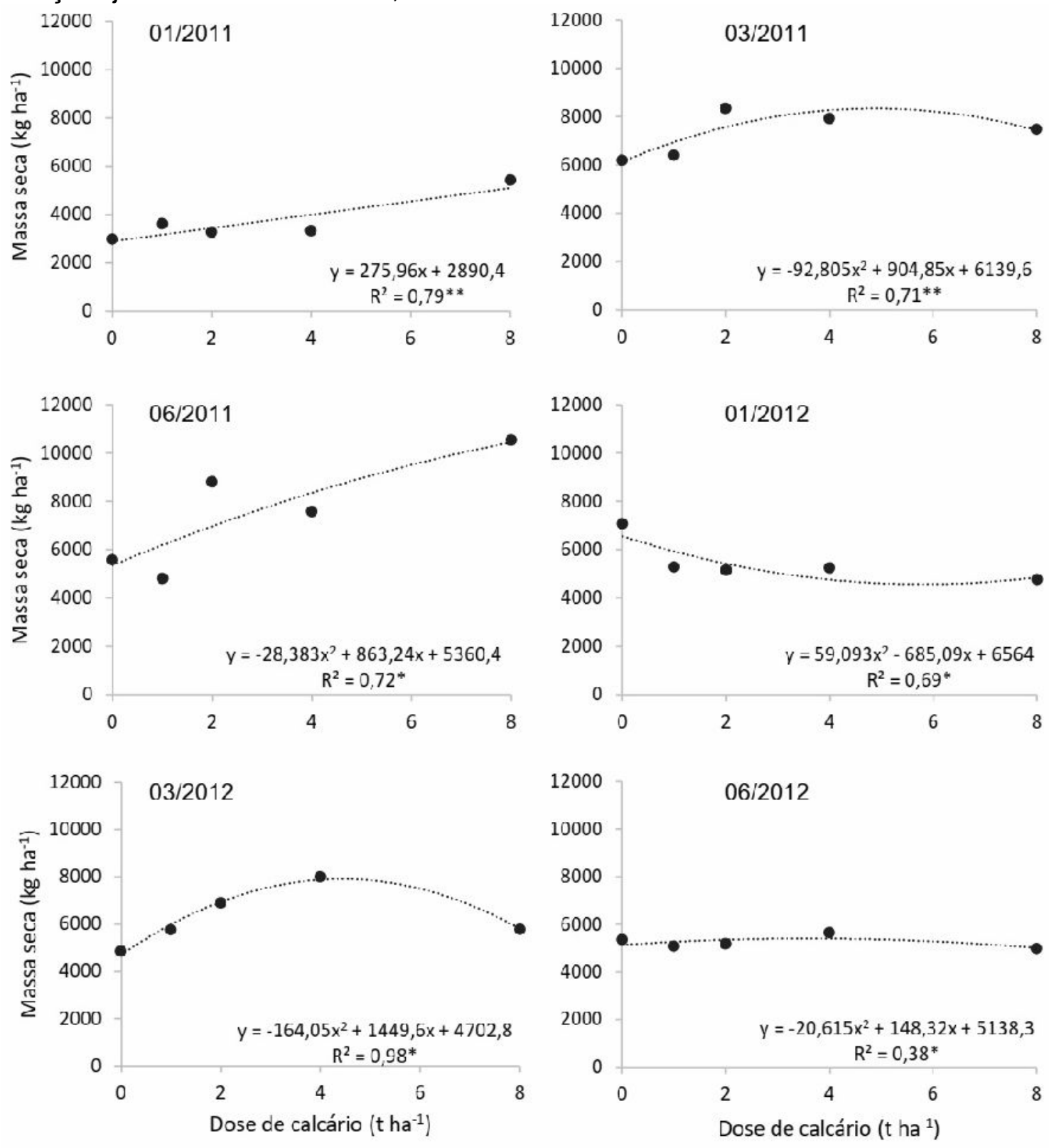

${ }^{* *}$ significativo a $1 \%,{ }^{*}$ significativo a $5 \%$.

Fonte: os autores. 
FIGURA 3. Rendimento de massa seca do capim-marandu nos meses de janeiro, março e junho de 2011 e 2012, com doses crescentes de nitrogênio.
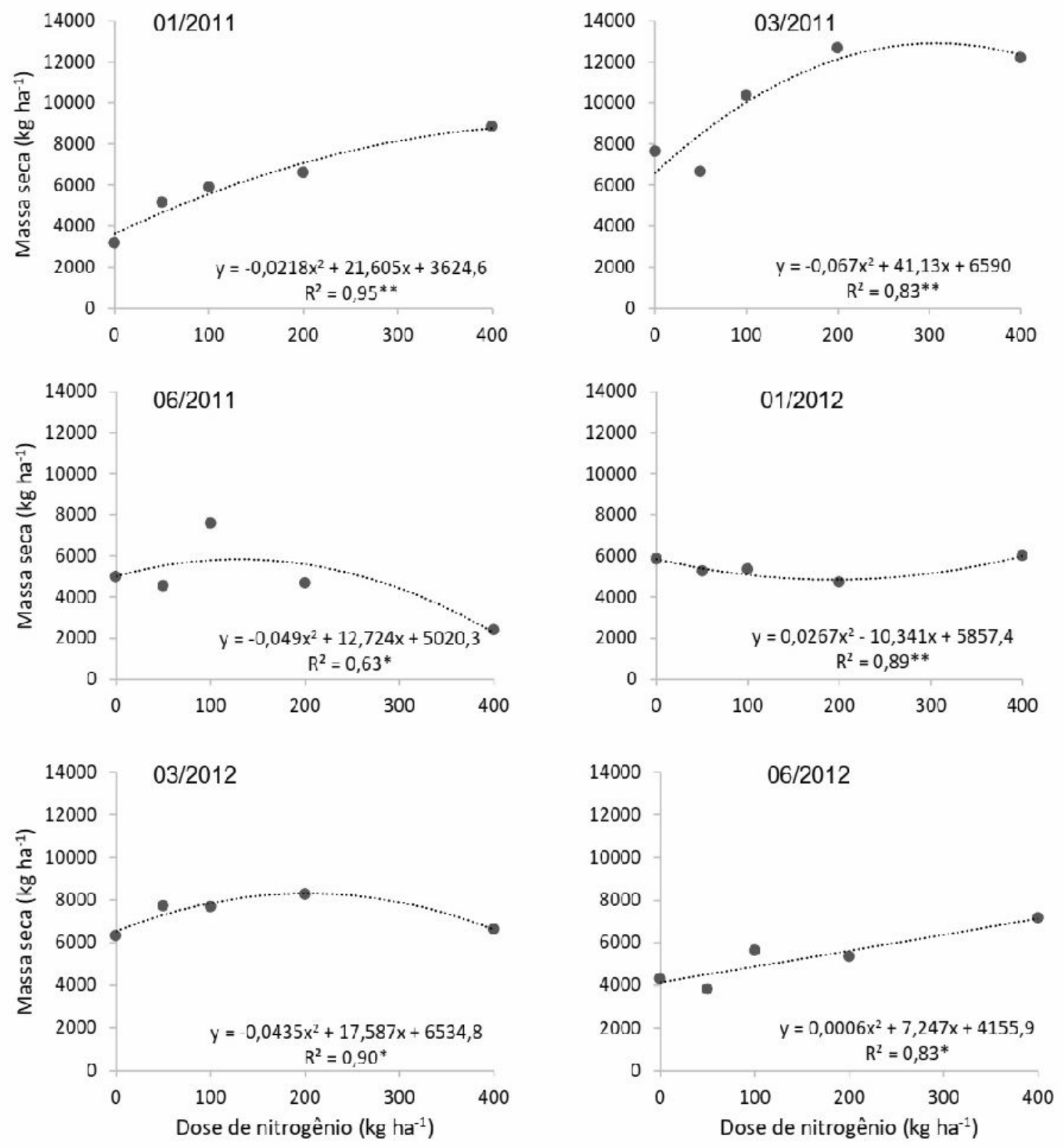

** significativo a $1 \%$, ${ }^{*}$ significativo a $5 \%$.

Fonte: os autores. 
FIGURA 4. Rendimento de massa seca do capim-marandu nos meses de janeiro, março e junho de 2011 e 2012, com doses crescentes de $\mathrm{K}_{2} \mathrm{O}$.
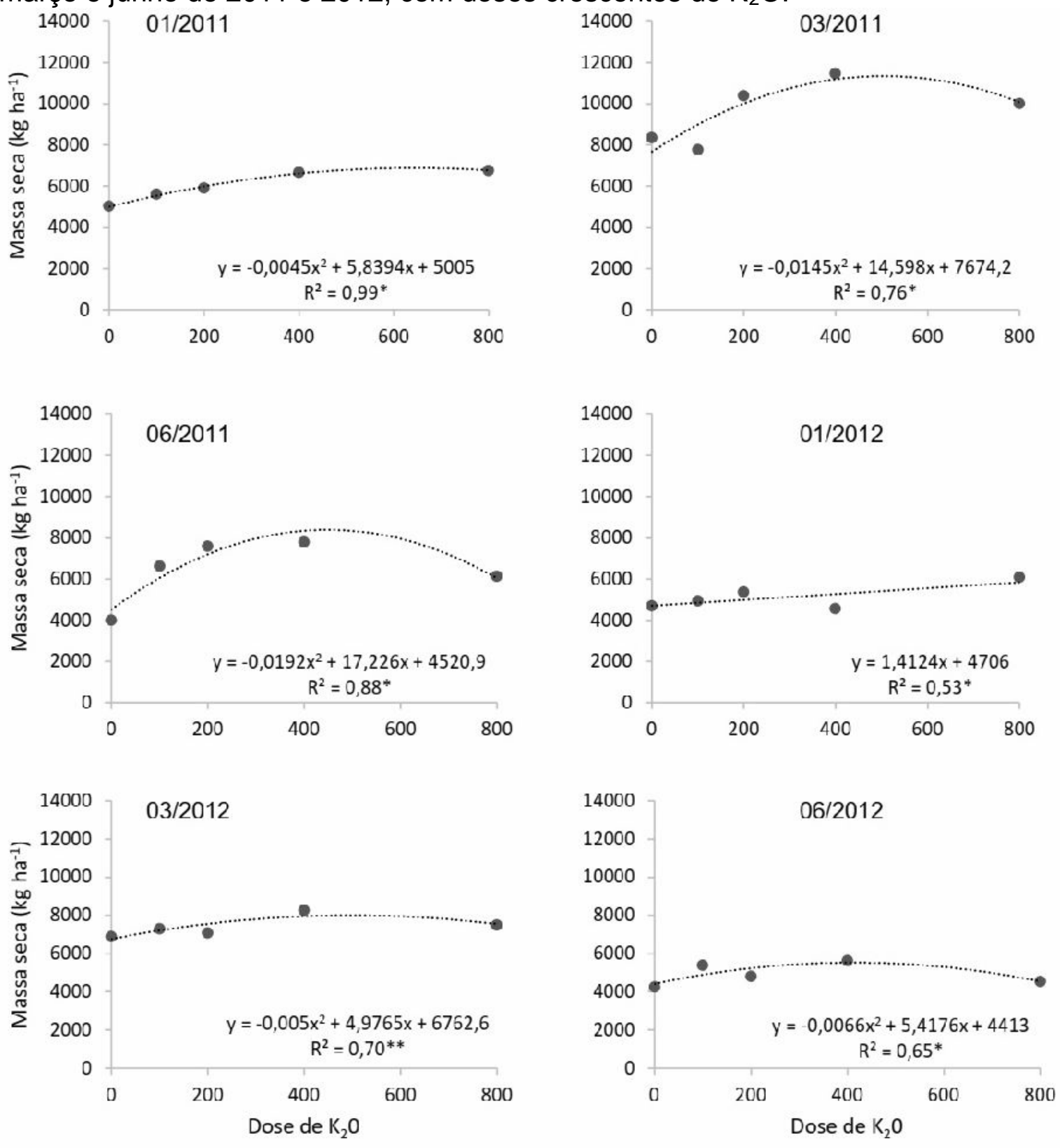

** significativo a $1 \%,{ }^{*}$ significativo a $5 \%$.

Fonte: os autores.

As funções polinomiais da Tabela 2 foram obtidas pela média de massa seca do capim-marandu avaliados nos cortes de janeiro, fevereiro e junho de 2011 e 2012 (Figura 1, 2, 3 e 4). Essas funções médias também foram utilizadas para estimar das doses de máxima eficiência técnica e econômica (Tabela 3). 
TABELA 2. Função polinomial média e coeficiente de determinação médio para avaliações de rendimento do capim-marandu de 2011 e 2012, com doses de calcário, $\mathrm{P}_{2} \mathrm{O}_{5}, \mathrm{~K}_{2} \mathrm{O}$ e $\mathrm{N}$.

\begin{tabular}{|c|c|c|c|}
\hline & Fertilizante & Função polinomial & $\mathbf{R}^{2}$ \\
\hline & Calcário & $\mathrm{y}=-77,604 \mathrm{x}^{2}+731,57 \mathrm{x}+4879$ & 0,88 \\
\hline & $\mathrm{P}_{2} \mathrm{O}_{5}$ & $\mathrm{Y}=-0,010 \mathrm{x}^{2}+10,26 \mathrm{x}+4614$ & 0,94 \\
\hline & $\mathrm{K}_{2} \mathrm{O}$ & $\mathrm{Y}=-0,008 \mathrm{x}^{2}+5,37 \mathrm{x}+5846$ & 0,76 \\
\hline & $\mathrm{N}$ & $\mathrm{Y}=-0,042 \mathrm{x}^{2}+17,66 \mathrm{x}+5473$ & 0,83 \\
\hline
\end{tabular}

As funções polinomiais médias demostraram que, quando os demais nutrientes do solo estiverem com teores supostamente adequados, as adições de calcário, fósforo, potássio e nitrogênio, isoladamente responderam significativamente às adições de doses crescentes. Verificou-se que o calcário foi o mais responsivo, tendo aumento estimado de $731,57 \mathrm{~kg}$ de massa seca do capim-marandu para cada tonelada de calcário aplicada no solo. O nitrogênio foi o segundo que mais respondeu, tendo aumento estimado de $17,66 \mathrm{~kg}$ de massa seca do capim-marandu para cada $\mathrm{kg}$ de nitrogênio aplicado no solo. O fósforo foi o terceiro que mais respondeu e, o aumento estimado foi de $10,26 \mathrm{~kg}$ de massa seca para cada $\mathrm{kg}$ de $\mathrm{P}_{2} \mathrm{O}_{5}$ aplicado no solo. $\mathrm{O}$ potássio foi o quarto, tendo aumento estimado de $5,37 \mathrm{~kg}$ de massa seca para cada $\mathrm{kg}$ de $\mathrm{K}_{2} \mathrm{O}$ aplicado no solo.

As respostas significativas em massa seca do capim-marandu para adições crescentes de calcário devem ser pelo aumento esperado no pH do solo, já que ele era baixo (Tabela 1) e isso faz aumentar a eficiência de nutrientes do solo e os que foram aplicados, aumentam as atividades biológicas e também diminuem os teores de elementos tóxicos (TAIZ et al., 2017). Isso tudo pode propiciar um ambiente de solo melhor para as plantas que ali estão crescendo.

À medida que aumenta o teor de nitrogênio no solo, ocorre o incremento na proporção de folhas e maior área foliar fotossinteticamente ativa que consequentemente promove maior acúmulo de matéria seca (SKINNER, 2013).

Um ponto desfavorável dos adubos fosfatados é que parte do fósforo aplicado pode ficar retido na fase sólida do solo após sua dissolução, sendo que a intensidade do aproveitamento desse nutriente depende, principalmente, da espécie cultivada, da textura do solo, da qualidade dos minerais de argila e da acidez do solo, além da dose, fonte de $\mathrm{P}$ e a forma de aplicação, além do sistema de preparo do solo. As braquiárias possuem alta capacidade de absorver formas de $\mathrm{P}$ do solo que outras culturas não têm acesso, devido a recuperação dos nutrientes em profundidade, o que diminui bastante a exigência de adubação fosfatada na fase de manutenção (SOUSA; LOBATO, 2004).

O aumento da produção de forragem com a adubação potássica deve-se as várias funções que o potássio tem na fisiologia da planta como no processo de regulação do potencial osmótico das células, ativador de várias enzimas envolvidas na respiração e fotossíntese, participação na translocação de carboidratos, aumenta a resistência doenças e ao acamamento (TAIZ et al., 2017).

As plantas da pastagem responderam positivamente ao aumento das doses de calcário, fósforo, potássio e nitrogênio, aumentando a produtividade até a dose máxima técnica estimada de 5874, 493, 351 e $209 \mathrm{~kg} \mathrm{ha}^{-1}$ respectivamente (Tabela 4). As doses 
de máxima eficiência técnica e econômica são relativamente grandes, devido aos baixos níveis de fertilidade desse solo (Tabela 1).

Tabela 3. Média da dose de calcário, $\mathrm{P}_{2} \mathrm{O}_{5}, \mathrm{~K}_{2} \mathrm{O}$ e $\mathrm{N}$ e da produção acumulada de massa seca para a máxima eficiência técnica e econômica.

\begin{tabular}{|c|c|c|c|c|}
\hline \multirow{2}{*}{ Fertilizante } & \multicolumn{2}{|c|}{$\mathrm{MET}^{(1)}$} & \multicolumn{2}{|c|}{$\mathrm{MEE}^{(1)}$} \\
\hline & Dose & MS & Dose & MS \\
\hline & ----------- & -------- & --------. & --------------- \\
\hline Calcário & 5874 & 6832 & 5859 & 7109 \\
\hline $\mathrm{P}_{2} \mathrm{O}_{5}$ & 493 & 8609 & 399 & 8458 \\
\hline $\mathrm{K}_{2} \mathrm{O}$ & 351 & 6789 & 223 & 6664 \\
\hline $\mathrm{N}$ & 209 & 7324 & 183 & 7237 \\
\hline
\end{tabular}

(1) MET: máxima eficiência técnica, MEE: máxima eficiência econômica com critério de capital ilimitado.

As doses do calcário e adubos em estudo proporcionaram a maior produtividade de MS com as doses de MET superiores a produtividade com as doses de MEE, o que indica que a calagem e a adubação devem ser realizadas de forma cuidadosa a manter condições favoráveis de retorno financeiro e garantir o desenvolvimento vegetativo das plantas.

As maiores produtividades na dose MEE foram com dose de $5859 \mathrm{~kg} \mathrm{ha}^{-1}$ de calcário, com dose de $399 \mathrm{~kg} \mathrm{ha}^{-1}$ de $\mathrm{P}_{2} \mathrm{O}_{5}$, com dose de $223 \mathrm{~kg} \mathrm{ha}^{-1}$ de $\mathrm{K}_{2} \mathrm{O}$ e com dose de $183 \mathrm{~kg} \mathrm{ha}^{-1}$ de $\mathrm{N}$, com produção de MS de 7109, 8458, 6664, $7237 \mathrm{~kg} \mathrm{ha}^{-1}$, respectivamente.

Schlindwein; Gianelo (2005) encontraram tendências semelhantes nos cálculos de doses de máxima eficiência técnica e econômica para as culturas de soja, trigo e milho cultivados em solos adubados anualmente, sendo que as doses de máxima eficiência econômica variaram de 109 a $141 \mathrm{~kg} \mathrm{ha}^{-1}$ de $\mathrm{P}_{2} \mathrm{O}_{5}$ e de 49 a $120 \mathrm{~kg} \mathrm{ha}^{-1}$ de $\mathrm{K}_{2} \mathrm{O}$.

\section{CONCLUSÃO}

As doses crescentes de calcário e do adubo fosfatado, potássico e nitrogenado proporcionaram aumentos de produtividade de massa seca do capim-marandu, sendo possível calcular as doses de máxima eficiência técnica e econômica.

No cenário de preços do calcário, dos fertilizantes, da carne bovina e das condições de condução dos experimentos, as doses de máxima eficiência econômica para calagem é $5.600 \mathrm{~kg} \mathrm{ha}^{-1}$, fósforo é $400 \mathrm{~kg} \mathrm{ha}^{-1}$, potássio é $220 \mathrm{~kg} \mathrm{ha}^{-1}$ e nitrogênio é $180 \mathrm{~kg} \mathrm{ha}^{-1}$.

\section{AGRADECIMENTO}

Agradecemos ao Dr. Volmir Dionísio Rodegheri proprietário do imóvel incentivador e financiador do experimento, alunos bolsistas que ajudaram nas atividades de campo (Ariane Evald, Everson Massocato, Karina Galvão, Gleice Bento e Thiago Boni). 
AGROLINK.

REFERÊNCIAS

$<$ https://www.agrolink.com.br/cotacoes/historico/sc/boi-gordo-15kg>. Acesso em: 20 de dezembro de 2020.

ANUALPEC. Anuário da Pecuária Brasileira 2019. 26 ed. São Paulo: Instituto FNP, 2019. $400 \mathrm{p}$.

BARCEloS, A. F.; LIMA, J. A.; PEREIRA, J. P.; GUIMARÃES, P. T. G.; EVANGELISTA, A. R.; GONÇALVES, C. C. M. Adubação de capins do gênero Brachiaria. 1 ed. Belo Horizonte: EPAMIG, 2011. 84p.

BARCELLOS, A. D. O.; RAMOS, A. K. B.; VILELA, L.; BUENO JUNIOR, M. G. Sustentabilidade da produção animal baseada em pastagens consorciadas e no emprego de leguminosas exclusivas, na forma de banco de proteína, nos trópicos brasileiros. Revista Brasileira de Zootecnia, v. 7, (suplemento especial), p. 51-67, 2008. URL: <https://doi.org/10.1590/S1516-35982008001300008>. DOI: S151635982008001300008

BARIONI, L. G.; FERREIRA, A. C.; GUIMARÃES JÚNIOR, R.; MARTHA JÚNIOR, G. B.; RAMOS, A. Tabelas para estimativa de ingestão de matéria seca de bovinos de corte em crescimento em pastejo. Planaltina, DF: Embrapa Cerrados (Comunicado Técnico, 142), 2007.

BULEGON, L. G.; ZOZ, T.; CASTAGNARA, D. D.; KRUTZMANN, A.; MESQUITA, E. E.; NERES, M. A.; TAFFAREL, L. E. Residual effect of phosphorus fertilization on productivity and bromatologic composition of tropical forages. Revista de Ciências Agroveterinárias, $\quad$ v. $15, \quad$ n. 1, p. 16-23, 2016. URL: <https://doi.org/10.5965/223811711512016016>. DOI: $10.5965 / 223811711512016016$

EGUCHI, E. S.; CECATO, U.; MUNIZ, A. S.; SILVA, S. L.; CRUZ, C. Extração de minerais pelo capim marandu fertilizado com esterco de galinha sem e com escarificação. Revista Brasileira de Agropecuária Sustentável, v. 7, n. 3, p. 39-47, 2017. URL: <https://doi.org/10.21206/rbas.v7i3.407>. DOI: 10.21206/rbas.v7i3.407

FACTORI, M. A.; SILVA, P. C. G.; GONÇALVES, D. M.; SCATULIN NETO, A. S. N.; MARATTI, C. H. Z.; TIRITAN, C. S. Produtividade de massa de forragem e proteína bruta do capim mombaça irrigado em função da adubação nitrogenada. Colloquium Agrariae, v. $13, \quad$ n. $3, \quad$ p. 49-57, $2018 . \quad$ URL: $<$ http://journal.unoeste.br/index.php/ca/article/view/1882>. DOI: 10.5747/ca.2017.v13.n3.a173

FREITAS, G. A.; BENDITO, B. P. C.; SANTOS, A. C. M.; SOUSA, P. A. Diagnóstico ambiental de áreas de pastagens degradadas no município de Gurupi-TO. Biota Amazônia, v. 6, n. 1, p. 10-15, 2016. URL: <http://dx.doi.org/10.18561/2179$\underline{\text { 5746/biotaamazonia.v6n1p10-15> }}$. DOI: $10.18561 / 2179-5746$ 
HOTT, G. M. C.; ANDRADE, R. G.; HOTT, M. C.; MAGALHÃES JUNIOR, W. C. P. Monitoramento da cobertura verde e degradação de pastagens por meio de aplicativo mobile. Brazilian Journal of Animal and Environmental Research, v. 1, n. 2, 352361 , 2018.

URL:

https://www.alice.cnptia.embrapa.br/alice/bitstream/doc/1119495/1/ArtigoBrasJAnEnvRe sRicardoMonitoramento.pdf >.

IDARON. Agência de Defesa Sanitária Agrosilvopastoril do Estado de Rondônia. Rebanho bovino ultrapassa 14 milhões de cabeças em Rondônia. 2018. $<$ http://www.rondonia.ro.gov.br/rebanho-bovino-ultrapassa-14-milhoes-de-cabecas-emrondonia/>. Acesso em: 24 de maio de 2021.

PEREIRA, L. F.; FERREIRA, C. F. C.; GUIMARÃES, R. M. F. Manejo, qualidade e dinâmica da degradação de pastagens na Mata Atlântica de Minas GeraisBrasil. Nativa, v. 6 , n. 4 , p. 370-379, $2018 . \quad$ URL: <http://dx.doi.org/10.31413/nativa.v6i4.5542>. DOI: 10.31413/nativa.v6i4.5542

SCHLINDWEIN, J. A., GIANELLO, C. Doses de máxima eficiência econômica de fósforo e potássio para culturas cultivadas no sistema de Plantio Direto. Revista Plantio Direto. v. 85, n. 1, p. 20-25, 2005. URL: <https://doi.org/10.1590/S0100$\underline{06832008000500025}>$. DOI: $10.1590 /$ S0100-06832008000500025

SCHLINDWEIN, J. A.; MARCOLAN, A. L.; FIORELI-PERIRA, E. C.; PEQUENO, P. L. L.; J. S; MILITÃO, T. L. Solos de Rondônia: usos e perspectivas. Revista Brasileira de Ciências da Amazônia, v. 1, n. 1, p. 213-231, 2012. URL: <https://www.periodicos.unir.br/index.php/rolimdemoura/article/view/612/660 > .

SILVA, S. C.; CUNHA, W. F. Métodos indiretos para estimar a massa de forragem em pastos de Cynodon spp. Pesquisa Agropecuária Brasileira, v. 8, n. 38, p. 981-989, 2003. URL: <http://dx.doi.org/10.1590/S0100-204X2003000800011>. DOI: $10.1590 / \mathrm{s} 0100-204 \times 2003000800011$

SKINNER, R. H. Nitrogen fertilization effects on pasture photosynthesis, respiration, and ecosystem carbon content. Agriculture, Ecosystems and Environment; v. 172, p. 3541, 2013. URL: <https://doi.org/10.1016/j.agee.2013.04.005>. DOI: 10.1016/j.agee.2013.04.005

SOUSA, D. M. G.; LOBATO, E. (Ed.) Cerrado: correção do solo e adubação. 2. ed. Brasília: Embrapa, 2004.

SOUSA, D. S.; PEREIRA, W. E. Atividade Agrícola do brejo paraibano: declínio e tendências atuais. Revista Brasileira de Agropecuária Sustentável, v. 6, n. 3, p.1120, 2016. URL: <https://periodicos.ufv.br/rbas/article/view/2914/pdf>. DOI: $\underline{10.21206 / \text { rbas.v6i3.347 }}$

TAIZ, L., ZEIGER, E., MÜLLER, I. M., MURPHY, A. Fundamentos de Fisiologia Vegetal. 6. ed. Porto Alegre: Artmed, 2017. 888 p. 
TERRA, A. B. C.; FLORENTINO, L. A.; REZENDE, A. V. D.; SILVA, N. C. Leguminosas forrageiras na recuperação de pastagens no Brasil. Revista de Ciências Agrárias, v. 42, n. 2, p. 11-20, 2019. URL: <https://doi.org/10.19084/rca.16016>. DOI: $\underline{10.19084 / \text { rca. } 16016}$

TIESDALE, S. L.; NELSON, W. L.; BEATON, J. D. Soil Fertility and fertilizers. 5.ed. New York: Macmillan, 1993. 634 p. 